\title{
Silver and Gold Nanoparticles Embedded in Potato Starch Gel Films
}

\author{
Karen Khachatryan, Gohar Khachatryan, Maciej Fiedorowicz \\ Department of Chemistry and Physics, Agricultural University, Cracow, Poland \\ Email: rrchacza@cyf-kr.edu.pl
}

Received 26 November 2015; accepted 1 February 2016; published 6 February 2016

Copyright (C) 2016 by authors and Scientific Research Publishing Inc.

This work is licensed under the Creative Commons Attribution International License (CC BY). http://creativecommons.org/licenses/by/4.0/

(c) () Open Access

\begin{abstract}
Facile and environmentally friendly method of the preparation of silver and gold nanoparticles embedded in potato starch matrix (Sp) was developed. UVVIS spectroscopy, transmission electron microscopy (TEM) and Fourier transform infrared (FTIR) spectra confirmed formation of ball shaped Ag and Au nanoparticles situated within the polysaccharide template. EDS spectra confirm presence of silver and gold nanocrystals in the obtained composites. Differential scanning calorimetry (DSC) showed that Sp/Au composite started to decompose earlier. The decomposition is slower and two-step, in contrast to Sp and Sp/Ag. NanoAg accelerates carbonization. Molecular weights of polysaccharide chains of the matrix were estimated with the size exclusion chromatography coupled with multiangle laser light scattering and refractometric detectors (HPSEC-MALLSRI). Formation of nanosilver containing composites led to partial depolymerisation of polysaccharides from the amylose fraction. In the case of nanogold we observed depolymerisation of polysaccharide chains from both fractions.
\end{abstract}

\section{Keywords}

Nanocomposites, Polysaccharide Foils, Potato Starch Matrix, Potato Starch Template, Metal Nanoparticles

\section{Introduction}

For a wide spectrum of amazing properties metal nanoparticles received much attention in a variety of areas including physics, chemistry, materials science, and biomedical science [1]. They are frequently used either in form of diluted solutions ready for application in form of sprays or ready to use suspensions, for instance, in glass or cosmetics. Their distribution on solid surfaces such as cloths is another possibility [2]-[6].

There are some arguments rationalizing this study. As all nanoparticles, also metal nanoparticles readily un-

How to cite this paper: Khachatryan, K., Khachatryan, G. and Fiedorowicz, M. (2016) Silver and Gold Nanoparticles Embedded in Potato Starch Gel Films. Journal of Materials Science and Chemical Engineering, 4, 22-31.

http://dx.doi.org/10.4236/msce.2016.42003 
dergo aggregation loosing their unique properties. Their disaggregation presents a task. Suspending these nanoparticles in starch foils would stabilize these nanoparticles from aggregation [7]. Since the matrix for these nanoparticles is biodegradable there should be a chance for controlled prolonged distribution of minute but significant concentration of nanoparticles suitable for their application as bactericidals [3]-[5] [8]-[10], fungicides [11] and catalysts [12]-[16]. For their provenience polysaccharides received attention as biodegradable environmentally benign materials of numerous applications, for instance, as packaging foils, encapsulating material, wound dressing and nanometal carriers [17]-[24]. Unfortunately, foils of plain starch appear too sensitive to microorganisms. Suspended metal nanoparticles might extend the period of safe application of the foils. Polysaccharides and their derivatives in which metal nanoparticles have been embedded usually contained functional groups providing anchoring the nanoparticles in the matrix and/or acting as reductors for metal cations, for instance, chitosan and its derivatives [18] [22] [23], heparin [19], glycosylamino glycans [20], starch dialdehyde [7], betachitin [21], hydroxymethylpropyl cellulose [17]. When polysaccharides did not contain such groups and did not dispose with sufficiently strong reducing properties, additional complexing agents such as thiolate, boronic acid, had been applied [24].

There is in a literature a growing concern about harm for the contact of organisms with nanoobjects. Nanoparticles are shown to affect the immunological system of living organisms [25]-[27]. For that sake opinion is presented that distribution of nanoparticles to the environment should be limited and taken under control. Recycling of materials containing nanoparticles, especially metal nanopowders and some quantum dots, is one of possible solutions in line with these suggestions. Suspending nanoparticles in biodegradable polysaccharide matrices would facilitate recycling of nanoparticles [28]-[31].

This paper presents preparation and characteristics of potato starch foils with embedded silver and gold nanoparticles generated from $\mathrm{AgNO}_{3}$ and $\mathrm{HAuCl}_{4}$, reduced with $\mathrm{NaBH}_{4}$. Potato starch is the sole native starch containing phosphate groups in its amylopectin component [10]. Such groups carrying negative charge when ionized can play a role of anchor for generated nanoparticles.

\section{Materials and Methods}

\subsection{Materials}

Potato starch (amylose: amylopectin ratio = 26\%:74\%; moisture content: $12 \%$ and phosphorus content: $550 \mathrm{ppm}$ ) was purchased from Pepees SA, Łomża, Poland. $\mathrm{AgNO}_{3}$ (99.99\%), $\mathrm{HAuCl}_{4}(\geq 99.9 \%$, trace metals basis) and $\mathrm{NaBH}_{4}$ (99.99\% trace metals basis) was purchased from Sigma-Aldrich.

\subsection{Synthesis of Metal Nanoparticles-Potato Starch (PS) Composites}

Potato starch (Sp), (5 g) was suspended in distilled water (95 mL). Resulted suspension was maintained on continuous agitation at $90^{\circ} \mathrm{C}$ for $2 \mathrm{~h}$ to produce a gel. Silver (PS/Ag) and gold $(\mathrm{Sp} / \mathrm{Au})$ nanocrystals were generated by addition to the starch gel either $\mathrm{AgNO}_{3}$ solution $\left(1 \mathrm{~mL} 0.05 \mathrm{M} / \mathrm{dm}^{3}\right)$ or $\mathrm{HAuCl}_{4}$ solution $(0.4 \mathrm{~mL}, 0.03$ $\mathrm{M} / \mathrm{dm}^{3}$ ), respectively, 30 min stirring this mixture followed by stepwise admixing $\mathrm{NaBH}_{4}$ aqueous solution (1 $\mathrm{mL}, 0.05 \mathrm{M} / \mathrm{dm}^{3}$ ). The reaction mixtures were agitated at the same temperature for $1 \mathrm{~h}$, then cooled and applied to a clean, smooth, defatted either Teflon or glass surface and left for drying in the air. The dry foils were stored in closed container.

\subsection{UV-VIS Absorption Spectrophotometry}

The UVVIS absorption spectra of, Sp Sp/nanoAg and Sp/nanoAu composites were recorded using a Shimadzu 2101 scanning spectrophotometer in the range of $200-700 \mathrm{~nm}$ using $10 \mathrm{~mL}, 10 \mathrm{~cm}$ thick quartz cells. Nanocomposite foils were dissolved in distilled water at $35^{\circ} \mathrm{C}-40^{\circ} \mathrm{C}$ to obtain solutions containing $0.001 \mathrm{~g} / \mathrm{L}$.

\subsection{FTIR-ATR Spectrophotometry}

The FTIR-ATR spectrum of the composites was recorded in the range of $500-4000 \mathrm{~cm}^{-1}$ at resolution of 4 $\mathrm{cm}^{-1}$ using a MATTSON 3000 FT-IR (Madison, Wisconsin, USA) spectrophotometer. That instrument was equipped with a 30SPEC 30 Degree Reflectance adapter fitted with the MIRacle ATR accessory from PIKE Technologies Inc., Madison, Wisconsin, USA. 


\subsection{Scanning and Transmission Electron Microscopy (SEM and TEM)}

Analyses of sizes and morphologies of the as-prepared nanoparticles were studied using a high resolution JEOL 7550 scanning electron microscope equipped with Energy dispersion X-ray spectroscopy (EDS) analyzer for local chemical analysis. Samples for TEM and SEM microscopies were prepared after drop-coating $10 \mu \mathrm{L}$ of the sample on a carbon-coated copper grid $\left(\mathrm{PELCO}^{\circledR}\right)$. Because the material was sufficiently conducting, the gold sputtering of the samples was dispensable.

\subsection{High Performance Size Exclusion Chromatography (HPSEC- MALLS-RI)}

Values of absolute molecular weight $\left(\mathrm{M}_{\mathrm{w}}\right)$ and radii of gyration $\left(\mathrm{R}_{\mathrm{G}}\right)$ of polysaccharide molecules from starch $(\mathrm{Sp})$ and silver $(\mathrm{Sp} / \mathrm{Ag})$ and gold $(\mathrm{Sp} / \mathrm{Au})$ were measured by means of high pressure size exclusion chromatography coupled with multiangle laser light scattering and refractometric index detectors (HPSEC-MALLS$\mathrm{RI})$.

The high performance size exclusion chromatography (HPSEC) system for determination of average molecular weight and radii of gyration consisted of a pump (Shimadzu 10AC, Tokyo, Japan), an injection valve (model 7021, Rheodyne, Palo Alto, CA, USA), a guard column TSK PWH (Tosoh Corporation, Tokyo, Japan), and two connected size exclusion columns TSKgel GMPWXL (300 $\times 7.8 \mathrm{~mm}$, Tosoh Corporation, Tokyo, Japan) and TSKgel 2500 PWXL (300 × 7.8 mm, Tosoh Corporation, Tokyo, Japan). A multiangle laser light scattering detector (MALLS) operating in chromatographic mode using a He-Ne laser light source $(630.0 \mathrm{~nm})$ (Dawn-DSP-F, Wyatt Technology, Santa Barbara, CA, USA) and a differential refractive index detector (L-7490, Merck, Darmstadt, Germany) were connected to the columns. The columns were maintained at $30^{\circ} \mathrm{C}$. The mobile phase ( $0.15 \mathrm{M} \mathrm{NaNO}_{3}$ with $0.02 \%$ sodium azide) was filtered through 0.2 and 0.1 microm cellulose acetate filters (Whatman, England). The flow rate of the mobile phase and the sample injection volume were $0.4 \mathrm{~mL} / \mathrm{min}$ and 500 microL respectively. The output voltage of refractive index (RI) and light scattering (LS) at 18 angles was used for calculation of the weight-average molecular weight $\left(M_{\mathrm{w}}\right)$ and radius of gyration $\left(R_{\mathrm{g}}\right)$ using Astra 4.73.04 software (Wyatt Technology, Santa Barbara, CA, USA).

Sp and nanocomposite samples $(100 \mathrm{mg})$ moistened with water $(10 \mathrm{~mL})$ were suspended in dimethylsulfoxide (DMSO, $90 \mathrm{~mL}$ ) then boiled for $12 \mathrm{~h}$ on agitation. Resulting solutions were filtered by $0.8 \mu \mathrm{m}$ cellulose acetate filters (Whatman, England) and immediately injected on chromatography column.

\subsection{Thermogravimetric Analysis (TG)}

For $\sim 5 \mathrm{mg}$ solid samples, the thermogravimetric analyses (TG) coupled with mass spectrometer (MS-TG/DTG/ SDTA) were performed in Mettler-Toledo 851e apparatus in $150 \mu$ l corundum crucibles, closed by a lid with a hole, under flow of argon $(80 \mathrm{~mL} / \mathrm{min})$, within temperature range $30^{\circ} \mathrm{C}-800^{\circ} \mathrm{C}$ with heating rate of $10^{\circ} \mathrm{C} / \mathrm{min}$. The simultaneous analysis of evolved gas (EGA) was performed during the experiments by joined on-line quadruple mass spectrometer (QMS) (Thermostar Balzers).

\subsection{Differential Scanning Calorimetry}

The differential scanning calorimetry (DSC) experiments for the $\sim 10 \mathrm{mg}$ samples were performed in MettlerToledo 821e calorimeter equipped with an intracooler Haake in 40 microL aluminum crucibles under constant flow of argon $(80 \mathrm{~mL} / \mathrm{min})$ within temperature range $25^{\circ} \mathrm{C}-400^{\circ} \mathrm{C}$.

\section{9. $\alpha$-Amylolysis}

$\alpha$-Amylase from porcine pancreas (EC.3.2.1.1,Merck, Darmstadt, Germany) was reconstituted in $20 \mathrm{mM}$ phosphate buffer (pH 6.5 - 7.0) containing $2 \mathrm{mM} \mathrm{NaCl}$ and $0.25 \mathrm{mM} \mathrm{CaCl}_{2}$ to obtain a stock solution with an enzyme activity of 250 units $/ \mathrm{mL}$. Nanocomposites were precisely weighed into Erlenmeyer flasks and suspended in the phosphate buffer $(38 \mathrm{~mL})$. Aliquots of the enzyme stock solution $(2 \mathrm{~mL})$ were added to achieve a 1 $\mathrm{mg} / \mathrm{mL}$ final concentration of amylopectin and a final enzyme activity of 12.5 units $/ \mathrm{mg}$ substrate. The Erlenmeyer flasks were incubated at $37^{\circ} \mathrm{C}$. The amount of maltose was determined by the 3,5-dinitrosalicylic acid method [32]. The extent of amylopectin amylolysis was calculated as the ratio of the amounts of hydrolysed amylopectin and total dry substrate. 


\section{Results and Discussion}

The UVVIS absorption spectra of potato starch and Sp/Ag and Sp/Au nanocomposites are presented Figure 1. Formation of strong absorption band centered at 410 and $580 \mathrm{~nm}$ in the case of Sp/Ag Sp/Au foils, respectively clearly suggest formation of $\mathrm{Ag}$ and Au nanoparticles embedded in starch matrix.

First, confirm that you have the correct template for your paper size. This template has been tailored for output on the custom paper size $(21 \mathrm{~cm} * 28.5 \mathrm{~cm})$.

Typical TEM images of silver (A) and gold (B) nanoparticles embedded in the starch matrix are displayed on Figure 2.

Spherical Ag and Au nanocrystals are well separated in starch matrix and particle size distribution ranges between 10 and $20 \mathrm{~nm}$ for both silver and gold nanostructures. EDS spectra of nanocomposites (Figure 3) fully confirm formation of silver and gold nanocrystals.

Morphology of polysaccharide matrix of Sp/Au and Sp/Ag composites distinguish from one another. The $\mathrm{Sp} / \mathrm{Au}$ sample seems to be amorphous whereas polysaccharide chains of $\mathrm{Sp} / \mathrm{Ag}$ composites form organized semicrystalline structures. Such differences in the matrix structures could be explained by substantial acid-catalyzed degradation of polysaccharide molecules in the presence of $\mathrm{HAuCl}_{4}$.

$\mathrm{M}_{\mathrm{w}}$ and $\mathrm{R}_{\mathrm{G}}$ of starch polysaccharide molecules for native starch (Sp) and silver (Sp/Ag) and gold (Sp/Au) nanocomposites, respectively, are presented in Table 1.

These results fit explanation of the differences between TEM images of Sp/Ag and Sp/Au. The whole chromatogram was, based on patterns, arbitrarily divided into two regions attributed to amylopectin (Fraction I) and amylose (Fraction 2) fractions, respectively. Under reaction condition, during formation of nanosilver in the starch matrix diminishing of $M_{w}$ of amylose molecules was observed together with rise of the $M_{w}$ of polysaccharide chains from amylopectin fraction as compared to native starch. Such effect indicates that formation of silver nanocrystals induced degradation of amylose chains. In the next step small chains from the amylose degradation add to the amylopectin chains. Formation of gold nanocrystals is associated with strong degradation of polysaccharide chains of both, amylose and amylopectin fraction. However, it is clear that amylopectin chains were more prone to degradation, up to complete depolymerization. Such effect, could explain great differences in morphology between Sp/Ag and Sp/Au nanocomposites observed on SEM images (Figure 2). FTIR spectra of potato starch (Sp) as well as Sp/Ag and Sp/Au composites are shown in Figure 4. In the fingerprint region, the spectra of potato starch and starch silver and gold nanocomposites have similar profiles with peaks at 1150, 1050 and $930 \mathrm{~cm}^{-1}$ which could be attributed to the C-O bond stretching vibrations [33].

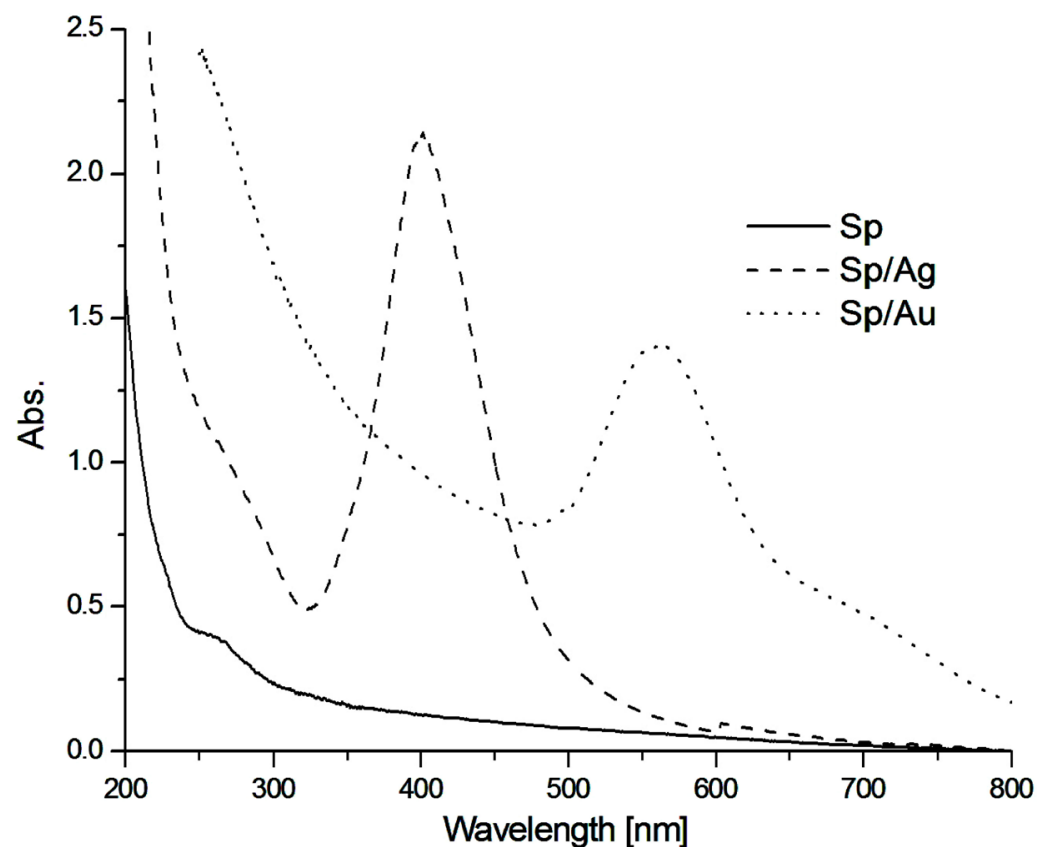

Figure 1. UVVIS spectra of potato starch (Sp), Sp/Ag and Sp/Au composites. 

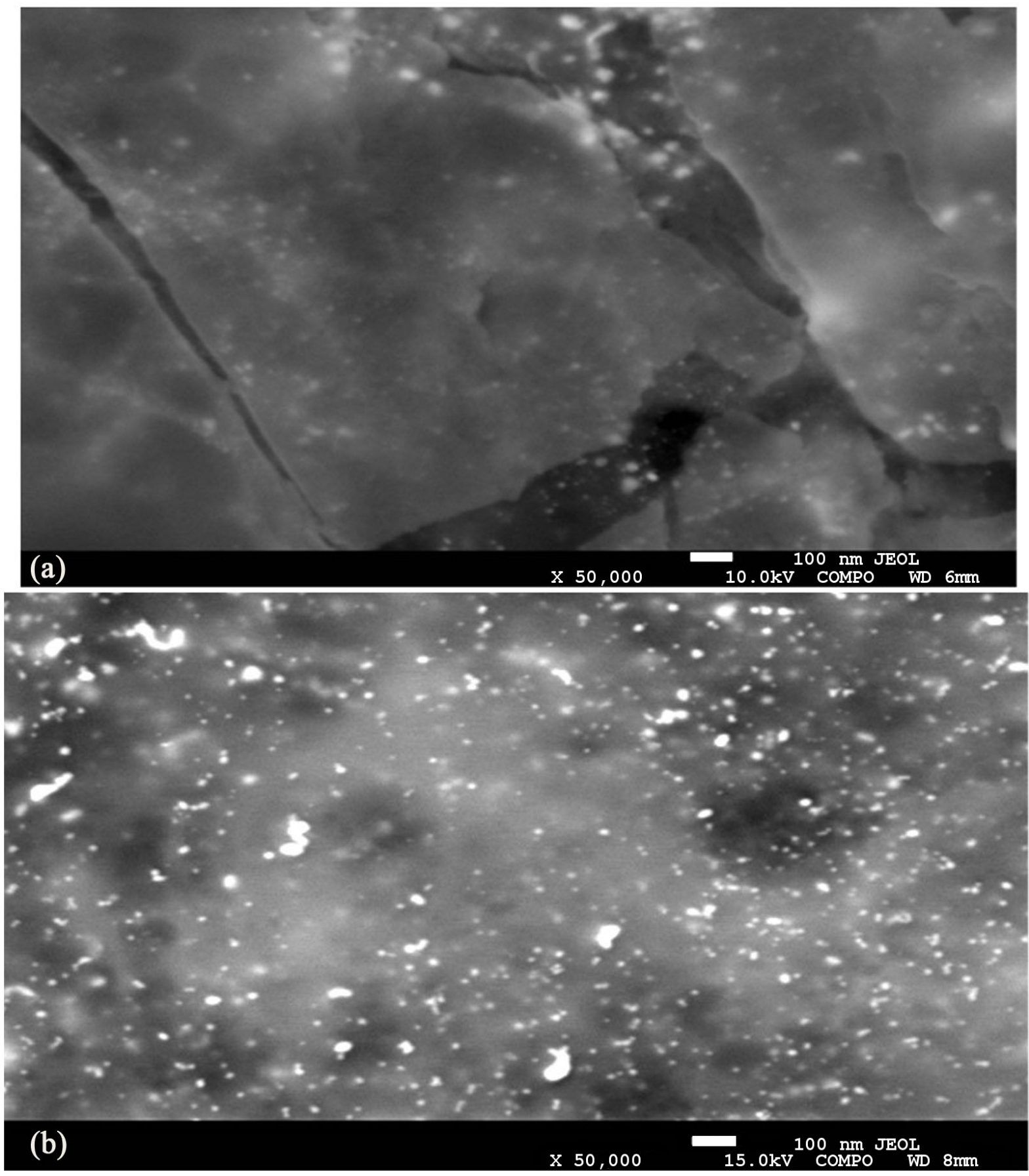

Figure 2. TEM images of Sp/Ag (a) and Sp/Au (b) composites.

Another characteristic band occurred on Sp and Sp/Ag spectra at $1652 \mathrm{~cm}^{-1}$. This peak originates from tightly bound water present in starch [34]. In the spectra of Sp/Au nanocomposite besides the absorption at $1652 \mathrm{~cm}^{-1}$, a additional broad peak centered at $1600 \mathrm{~cm}^{-1}$ could be seen. The latter reflects presence of water more loosely bound within more disrupted polysaccharide matrix of $\mathrm{Sp} / \mathrm{Au}$.

The pattern of the thermal decomposition (TG) of Sp and Sp/Ag (Figure 5) closely resemble one another. A slightly higher water content of in the latter sample resulted from a certain loosening the starch structure on processing starch towards the composite.

The theromogram of Sp/Au confirms essential degradation of the polysaccharide in that composite. Because 


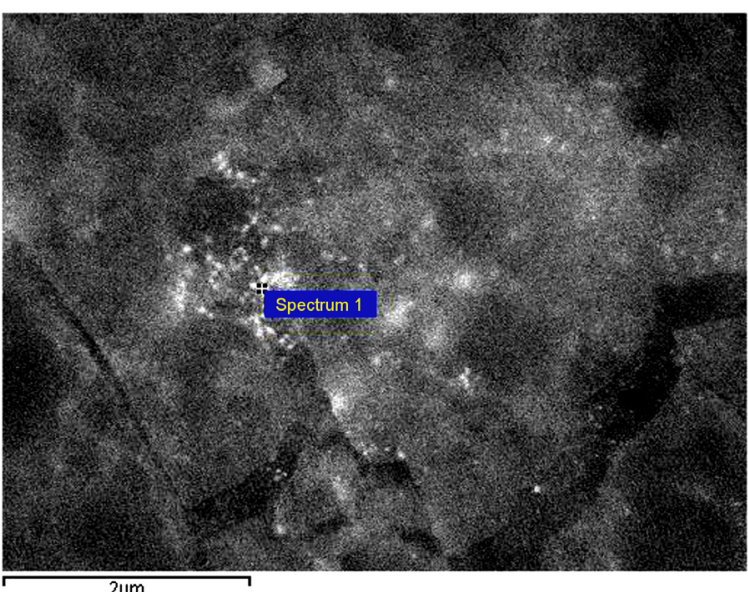

(a)

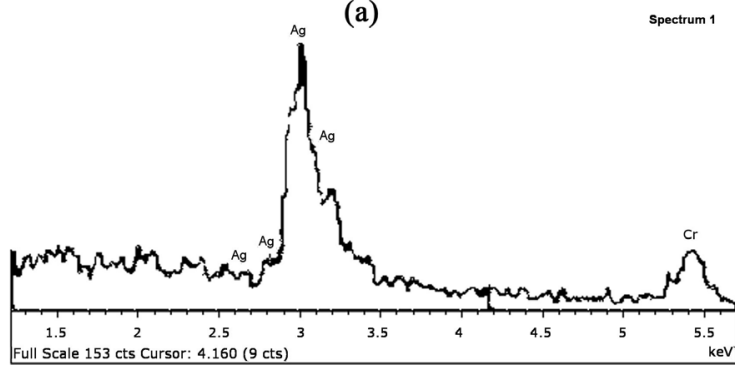

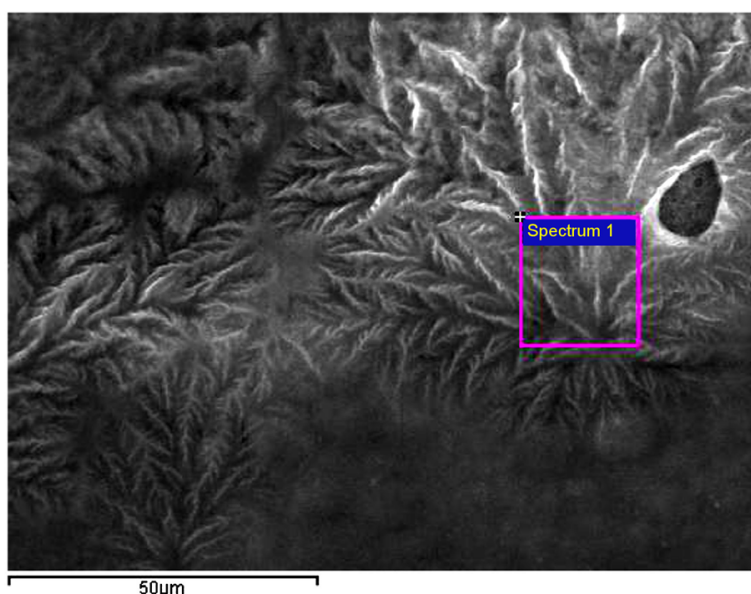

(b)

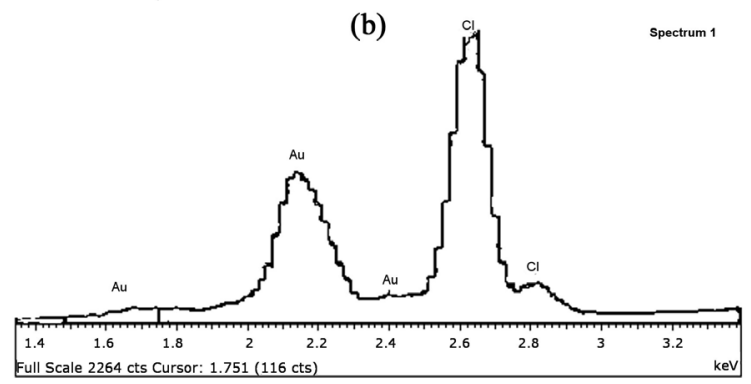

Figure 3. EDS spectra of Sp/Ag (a) and Sp/Au (b) composites.

Table 1. Absolute molecular weight of the original starch fractions and their changes after generation of nanoAg (Sp/Ag) and nanoAu crystals inside starch gel (Rg, radius of gyration).

\begin{tabular}{ccccc}
\hline & $\mathrm{M}_{\mathrm{w}} \times 10^{7}$ & $\mathrm{M}_{\mathrm{w}} \times 10^{7}$ & $\mathrm{Rg}$ & $\mathrm{Rg}$ \\
\cline { 2 - 5 } Sample & Fraction I & Fraction II & Fraction I (nm) & 105.8 \\
Sp & 3.87 & 3.64 & 89.0 & 101.3 \\
Sp/Ag & 4.20 & 3.18 & none & 51.9
\end{tabular}

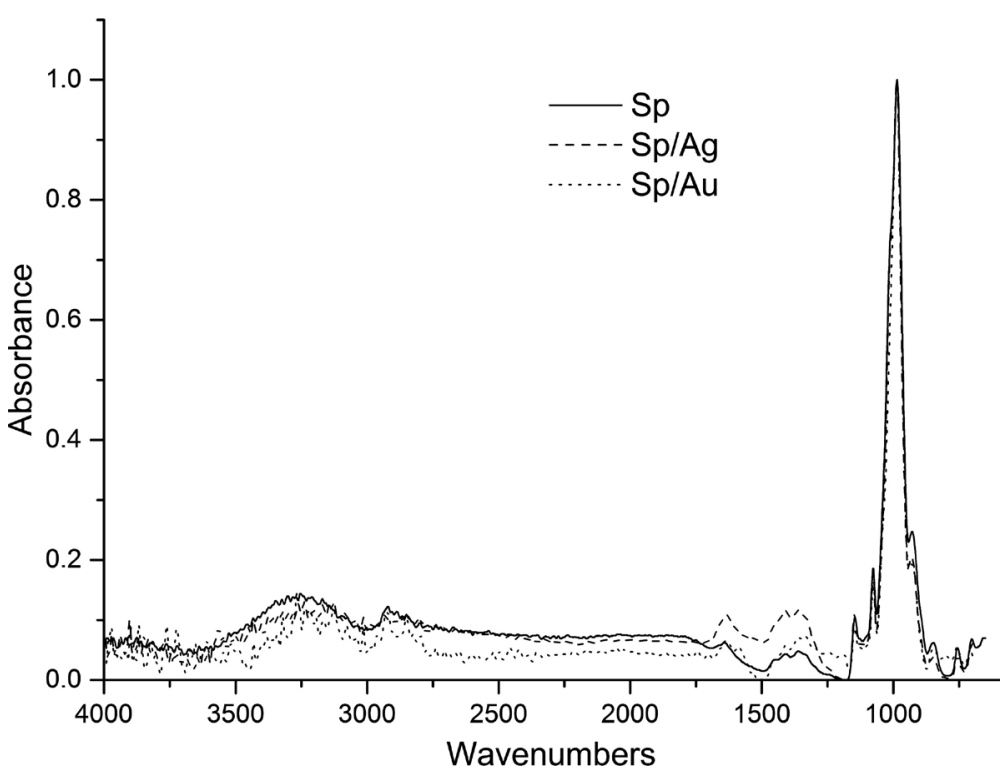

Figure 4. The FTIR spectra of Sp, Sp/Ag and Sp/Au composites. 
of the degradation, it contained less humidity, only slightly more than unprocessed starch. Because of the deeper interference into the native structure also stabilizing intermolecular hydrogen bonds partly ceased and due to depolymerization the structure became more non-uniform. The composite started to decompose by approximately $100^{\circ} \mathrm{C}$ earlier, the decomposition is slower, and in contrast to $\mathrm{Sp}$ and $\mathrm{Sp} / \mathrm{Ag}$ two-step. Also the hightemperature decomposition pattern of $\mathrm{Sp}$ and $\mathrm{Sp} / \mathrm{Ag}$ are essentially different. NanoAg accelerates carbonization. In $\mathrm{Sp} / \mathrm{Ag}$ it is completed at around $340^{\circ} \mathrm{C}$ and further heating caused burning the carbonizate out leaving at $600^{\circ} \mathrm{C}$ approximately $20 \%$ residue. The decomposition pattern of $\mathrm{Sp} / \mathrm{Au}$ in this temperature range resembled decomposition of plain Sp. At $600^{\circ} \mathrm{C}$ both samples left approximately $30 \%$ residue. It pointed to the presence of silver oxide on thermolyzed Sp/Ag which promoted deeper burning out the carbonizate.

DSC thermograms registered for and Sp/Ag and Sp/Au nanocomposites together with the thermogram of Sp are displayed on Figure 6.

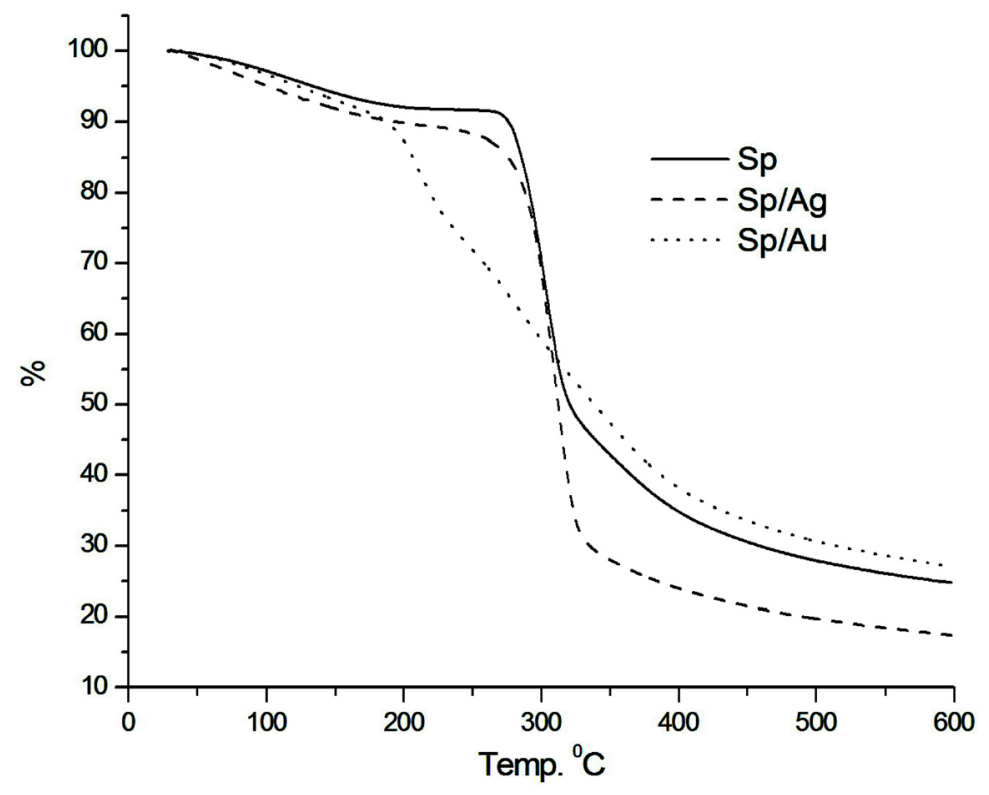

Figure 5. TG analysis of Sp, Sp/Ag and Sp/Au.

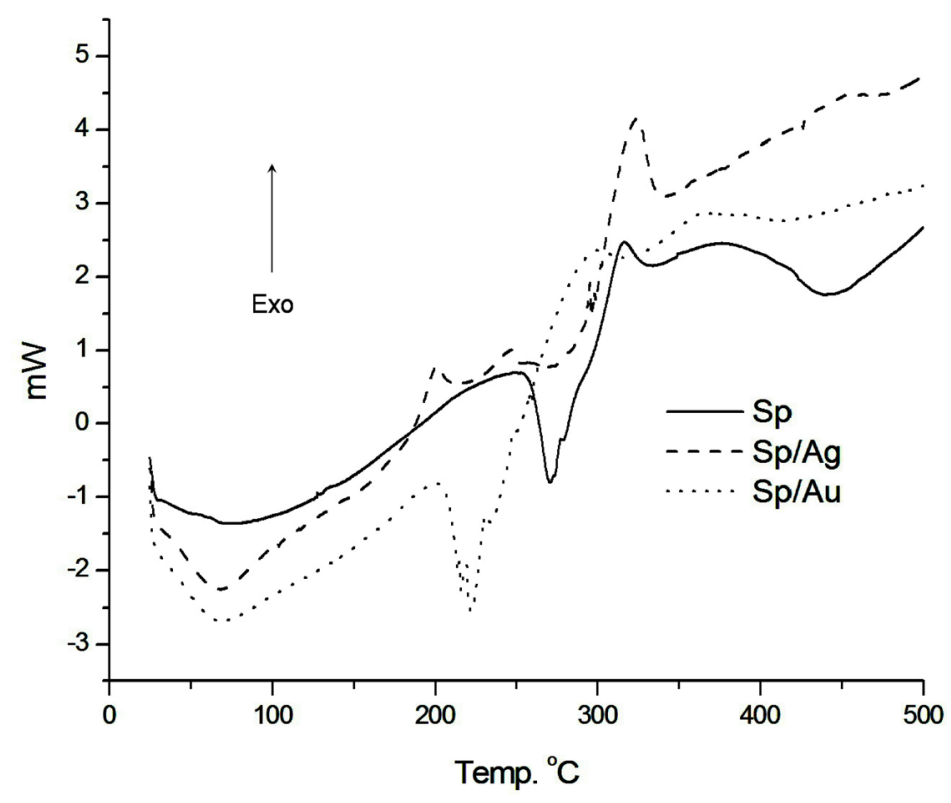

Figure 6. DSC thermograms of Sp, Sp/Ag and Sp/Au composites. 
The shapes of the thermograms taken for starch and $\mathrm{Sp} / \mathrm{Au}$ composite, consisting roughly of one endothermic and one exothermic peak, are similar to some extent. In both cases exothermic peak centered at $310^{\circ} \mathrm{C}$ for $\mathrm{Sp}$ and $320^{\circ} \mathrm{C}$ for $\mathrm{Sp} / \mathrm{Au}$ could be attributed to decomposition of the polymer. Temperature of endothermic transition for $\mathrm{Sp} / \mathrm{Au}$ nanocomposite $\left(220^{\circ} \mathrm{C}\right)$ is much lower than temperature of such transition recorded for starch indicating disintegration of polysaccharide matrix during nanogold formation. DSC thermogram patterns observed for $\mathrm{Sp} / \mathrm{Ag}$ differs greatly from thermograms of starch and starch silver nanocomposite. Two exothermic peaks one at $200^{\circ} \mathrm{C}$ and second at $330^{\circ} \mathrm{C}$ could be observed indicating that silver nanocrystals formation leads to the more ordered orientation of polysaccharide chains as compared with starch and $\mathrm{Sp} / \mathrm{Au}$ composite. Thermal properties of starch and starch silver ( $\mathrm{Sp} / \mathrm{Ag}$ ) and gold (Sp/Au) nanocomposites are in good agreement with results of molecular weight measurements of polysaccharide chains constituting starch nanometals composites.

Silver and gold nanoparticles embedded in the potato starch foil very efficiently inhibit these foils against several hydrolases. Results of these studies will be published separately.

\section{Conclusions}

Silver and gold nanoparticles were successfully formed in potato starch matrix. Polysaccharide matrix makes nanometals stable and prevents from aggregation.

1) Potato starch is suitable matrix for silver and gold nanoparticles.

2) When $\mathrm{HAuCl}_{4}$ is applied as a source for nanoparticles, generation of the nanoparticles is accompanied by acid-catalyzed depolymerization of gelatinized starch.

3) Foils can be drawn from gelatinized starch suspensions of silver and gold nanoparticles in the manner avoiding agglomeration of suspended nanoparticles.

\section{References}

[1] Datta, K.K., Srinivasan, B., Balaram, H. and Eswaramoorthy, M. (2008) Synthesis of Agarose-Metal/Semiconductor Nanoparticles Having Superior Bacteriocidal Activity and Their Simple Conversion to Metal-Carbon Composites. Journal of Chemical Sciences, 120, 579-586. http://dx.doi.org/10.1007/s12039-008-0088-y

[2] Duran, N., Marcato, P.D., De Souza, G.I.H., Alves, O.L. and Esposito, E., (2007) Antibacterial Effect of Silver Nanoparticles Produced by Fungal Process on Textile Fabrics and Their Effluent Treatment. Journal of Biomedical Nanotechnology, 3, 203-208. http://dx.doi.org/10.1166/jbn.2007.022

[3] Ip, M., Sau, L.L., Pooy, V.K.M., Lung, I. and Bud, A. (2006) Antimicrobial Activities of Silver Dressings: An in Vitro Comparison. Journal of Medical Microbiology, 55, 59-63. http://dx.doi.org/10.1099/jmm.0.46124-0

[4] Lee, W. and Huang, Y. (2007) Swelling and Antibacterial Properties for the Superabsorbent Hydrogels Containing Silver Nanoparticles. Journal of Applied Polymer Science, 106, 1992-1999. http://dx.doi.org/10.1002/app.26906

[5] Sondi, I. and Salopek-Sondi, B. (2004) Silver Nanoparticles as Antimicrobial Agent: A Case Study on E. coli as a Model for Gram-Negative Bacteria. Journal of Colloid and Interface Science, 275, 177-182.

http://dx.doi.org/10.1016/j.jcis.2004.02.012

[6] Thomas, V., Yallapu, M.M., Seedhar, B. and Baipai, S.K. (2007) A Versatile Strategy to Fabricate Hydrogel—Silver Nanocomposites and Investigation of Their Antimicrobial Activity. Journal of Colloid and Interface Science, 315, 389-395. http://dx.doi.org/10.1016/j.jcis.2007.06.068

[7] Khachatryan, K., Khachatryan, G., Fiedorowicz, M., Para, A. and Tomasik, P. (2013) Formation of Nanometal Particles in the Dialdehyde Starch Matrix. Carbohydrate Polymers, 98, 568-573. http://dx.doi.org/10.1016/j.carbpol.2013.06.032

[8] Merchant, B. (1998) Gold, the Noble Metal and the Paradoxes of Its Toxicology. Biologicals, 26, 49-59. http://dx.doi.org/10.1006/biol.1997.0123

[9] Pal, S., Tak, Y.K. and Song, J.M. (2007) Does the Antibacterial Activity of Silver Nanoparticles Depend on the Shape of the Nanoparticle? A Study of the Gram-Negative Bacterium Escherichia coli. Applied and Environmental Microbiology, 73, 1712-1720. http://dx.doi.org/10.1128/AEM.02218-06

[10] Tomasik, P. (2009) Specific Physical and Chemical Properties of Potato Starch. In: Teixeira da Silva, J., Ed., Food 3 (Special issue 1), Global Science Books, New York, 45-56.

[11] Sawinska, Z., Khachatryan, K., Sobiech, Ł., Idziak., R. and Kosiada, T. (2014) Use of Silver Nanoparticles as a Fungicide. Przemyst Chemiczny, 93, 1472-1474. http://dx.doi.org/10.12916/przemchem.2014.1472

[12] Choudhary, V.R., Patil, V.P., Jana, P. and Uphade, B.S. (2008) Nano-Gold Supported on $\mathrm{Fe}_{2} \mathrm{O}_{3}$ : A Highly Active Catalyst for Low Temperature Oxidative Destruction of Methane Green House Gas from Exhaust/Waste Gases. Applied 
Catalysis A, 350, 186-190. http://dx.doi.org/10.1016/j.apcata.2008.08.008

[13] Jiang, Z., Wen, G., Fan, Y., Jiang, C., Liu, Q., Huang, Z. and Liang, X. (2010) A Highly Selective Nanogold-Aptamer Catalytic Resonance Scattering Spectral Assay for Trace $\mathrm{Hg}^{2+}$ Using $\mathrm{HAuCl}(4)$-Ascorbic Acid as Indicator Reaction. Talanta, 80, 1287-1291. http://dx.doi.org/10.1016/j.talanta.2009.09.026

[14] Ma, Z.F. and Sui, S.I. (2002) Naked-Eye Sensitive Detection of Immunoglubulin G by Enlargement of Au Nanoparticles in Vitro. Angewandte Chemie International Edition, 41, 2176-2178. http://dx.doi.org/10.1002/1521-3773(20020617)41:12<2176::AID-ANIE2176>3.0.CO;2-X

[15] Qi, C. (2008) The Production of Propylene Oxide over Nanometer Au Catalysts in Presence of $\mathrm{H}_{2}$ and $\mathrm{O}_{2}$. Gold Bulletin, 41, 224-234. http://dx.doi.org/10.1007/BF03214874

[16] Shi, F., Zhang, Q., Ma, Y., He, Y. and Deng, Y. (2005) From CO Oxidation to $\mathrm{CO}_{2}$ Activation: An Unexpected Catalytic Activity of Polymer-Supported Nanogold. Journal of the American Chemical Society, 127, 4182-4183. http://dx.doi.org/10.1021/ja042207o

[17] Dabbagh, M.A., Moghimipour, E., Ameri, A. and Sayfoddin, N. (2007) Physicochemical Characterization and Antimicrobial Activity of Nanosilver Containing Hydrogels. Iranian Journal of Pharmaceutical Research, 7, 21-28.

[18] Huang, H. and Yang, X. (2004) Synthesis of Polysaccharide-Stabilized Gold and Silver Nanoparticles: A Green Method. Carbohydrate Research, 339, 2627-2631. http://dx.doi.org/10.1016/j.carres.2004.08.005

[19] Kemp, M.M., Kumar, A., Mousa, S., Dyskin, E., Yalcin, M., Ajayan, P., Linhardt, R.J. and Mousa, S. (2009) Gold and Silver Nanoparticles Conjugated with Heparin Derivative Possess Anti-Angiogenesis Properties. Nanotechnology, 20, Article ID: 455104. http://dx.doi.org/10.1088/0957-4484/20/45/455104

[20] Kemp, M.M., Kumar, A., Mousa, S., Park, T.J., Ajayan, P., Kubotera, N., Mousa, S.A. and Linhardt, R.J. (2009) Synthesis of Gold and Silver Nanoparticles Stabilized with Glycosaminoglycans Having Distinctive Biological Activities. Biomacromolecules, 10, 589-595. http://dx.doi.org/10.1021/bm801266t

[21] Kumar, S., Abhilash, S., Manzoor, K., Nair, S.V., Tamura, H. and Jayakumar, R. (2010) Preparation and Characterization of Novel $\beta$-Chitin/Nanosilver Composite Scaffolds for Wound Dressing Applications. Carbohydrate Polymers, 80, 761-767. http://dx.doi.org/10.1016/j.carbpol.2009.12.024

[22] Liang, Y.Y., Zhang, L.M., Jiang, W. and Li, W. (2007) Embedding Magnetic Nanoparticles into Polysaccharide-Based Hydrogels for Magnetically Assisted Bioseparation. ChemPhysChem, 8, 2367-2372. http://dx.doi.org/10.1002/cphc.200700359

[23] Traven, A., Pelillo, C., Donati, I., Marsich, E., Benincasa, M., Scarpa, T., Semerano, S., Turco, G., Gennero, R. and Paoletti, S. (2009) Non-Cytotoxic Silver Nanoparticle-Polysaccharide Nanocomposites with Antimicrobial Activity. Biomacromolecules, 10, 1429-1435. http://dx.doi.org/10.1021/bm900039x

[24] Zhang, J., Geddes, C.D. and Lakowicz, J.R. (2004) Complexation of Polysaccharide and Monosaccharide with Thiolate Boronic Acid Capped on Silver Nanoparticle. Analytical Biochemistry, 332, 253-260. http://dx.doi.org/10.1016/j.ab.2004.05.051

[25] Luo, Y.-H., Chang, L.W. and Lin, P. (2015) Metal-Based Nanoparticles and the Immune System: Activation, Inflammation, and Potential Applications. BioMed Research International, 2015, Article ID: 143720. http://dx.doi.org/10.1155/2015/143720

[26] Shukla, R., Bansal, V., Chaudhary, M., Basu, A., Bhonde, R. and Sastry, M. (2005) Biocompatibility of Gold Nanoparticles and Their Endocytotic Fate inside the Cellular Compartment: A Microscopic Overview. Langmuir, 21, 1064410654. http://dx.doi.org/10.1021/la0513712

[27] Parka, E.-J., Yib, J., Kimc, Y., Choid, K. and Parka, K. (2010) Silver Nanoparticles Induce Cytotoxicity by a TrojanHorse Type Mechanism. Toxicology in Vitro, 24, 872-878. http://dx.doi.org/10.1016/j.tiv.2009.12.001

[28] Dreher, K.L. (2004) Health and Environmental Impact of Nanotechnology: Toxicological Assessment of Manufactured Nanoparticles. Toxicological Sciences, 77, 3-5. http://dx.doi.org/10.1093/toxsci/kfh041

[29] Oberdoerster, G., Stone, V. and Donaldson, K. (2007) Toxicology of Nanoparticles: A Historical Perspective. NeuroToxicology, 1, 2-25. http://dx.doi.org/10.1080/17435390701314761

[30] Rothen-Rutishauser, B.M., Schuerch, S., Haenni, B., Kapp, N. and Gehr, P. (2006) Interaction of Fine Particles and Nanoparticles with Red Blood Cells Visualized with Advanced Microscopic Techniques. Environmental Science \& Technology, 40, 4353-4359. http://dx.doi.org/10.1021/es0522635

[31] SCENIHR (2006) European Commission, Health \& Consumer Protection, Directoriate-General. Scientific Committee on Energy and Newly Identified Health Risk. http://ec.europa.eu/health/ph_risk/committees/04_scenihr/docs/scenihr_o_003b.pdf

[32] Subramanian, V., Hoseney, R.C. and Bramel-Cox, P.J. (1994) Factors Affecting the Color and Appearance of Sorghum Starch. Cereal Chemistry, 71, 272-275. 
[33] Fang, J.M., Fowler, P.A., Sayers, C. and Williams, P.A. (2004) The Chemical Modification of a Range of Starches under Aqueous Reaction Conditions. Carbohydrate Polymers, 55, 283-289. http://dx.doi.org/10.1016/j.carbpol.2003.10.003

[34] Song, X., He, G., Ruan, H. and Chen, Q. (2006) Preparation and Properties of Octenyl Succinic Anhydride Modified Early Indica Rice Starch. Starch/Stärke, 58, 109-117. http://dx.doi.org/10.1002/star.200500444 